\title{
Performance evaluation of a modified offset rotavator in Guava orchard
}

\author{
SHARAD KUMAR NAMDEV, RAJNARAYAN PATERIYA, BHABANI SHANKAR DASH AND \\ RAJESH MODI
}

Received : 17.04.2017; Revised : 25.07.2017; Accepted : 09.08.2017

See end of the Paper for authors' affiliation Correspondence to :

SHARAD KUMAR NAMDEV

Department of Farm Machinery and Power Engineering, School of Agriculture, ITM University, GWALIOR (M.P.) INDIA Email : sharadsftr@gmail.com
-ABSTRACT : Rotary tillage implements are now projected as important tillage machinery for better seedbed preparation; however, the ordinary rotavator being in line with the tractor center line at the rear cannot be used in orchards due to the hindrance posed by narrow space between the plants. Therefore, the concept of a modified offset rotavator was proposed, which could perform intercultural operation between the plants. The study was conducted to evaluate the performance of the modified offset rotavator in guava orchard of Horticulture Research Center, Pantnagar. It was found that the draft (negative) for the L-shaped blades increased (1203.4 to $1841.4 \mathrm{~N}$ ) as the forward speed increased (2.0 to $3.0 \mathrm{~km} / \mathrm{h}$ ) with Increase in depth of cut (80 to 120 $\mathrm{mm}$ ) for the shield kept in the lowered (down) position and fuel consumption was higher $9.93 \mathrm{l} / \mathrm{h}$ at given forward speed $3.0 \mathrm{~km} / \mathrm{h}$ with $120 \mathrm{~mm}$ depth of cut. Soil break up (mean mass diameter) resulting from the Impact action of L-shaped blades on soil was found increased (1.05 to $1.95 \mathrm{~mm}$ ) as the forward speed increased $(2.0$ to $3.0 \mathrm{~km} / \mathrm{h})$. The extent of residue incorporation was the maximum $97.30 \%$ at forward speed $2.0 \mathrm{~km} / \mathrm{h}$ with $120 \mathrm{~mm}$ depth of cut, whereas at higher forward speed $3.0 \mathrm{~km} / \mathrm{h}$, field performance index was observed $88.28 \%$. The minimum area uncovered near the girth was reported $0.143 \mathrm{~m}^{2}$ at higher girth $0.48 \mathrm{~m}$ while plant injury at $3.0 \mathrm{~km} / \mathrm{h}$ resulted due to impact of sensing assembly with plants was found $50 \%$ in form of scratch on the girth.

- KEY WORDS : Tillage, Modified offset rotavator, Field performance, Guava orchard

- HOW TO CITE THIS PAPER : Namdev, Sharad Kumar, Pateriya, Rajnarayan, Dash' Bhabani Shankar and Modi, Rajesh (2017). Performance evaluation of a modified offset rotavator in Guava orchard. Internat. J. Agric. Engg., 10(2) : 347-353, DOI: 10.15740/HAS/IJAE/10.2/347-353. 